\title{
Knockout of $\alpha$-calcitonin gene-related peptide reduces cholangiocyte proliferation in bile duct ligated mice
}

\author{
Shannon S Glaser ${ }^{1,2}$, Yoshiyuki Ueno ${ }^{3}$, Sharon DeMorrow ${ }^{1,2}$, Valorie L Chiasson ${ }^{1}$, Khurshed A Katki ${ }^{1,2}$, Julie Venter ${ }^{1}$, \\ Heather L Francis ${ }^{2}$, lan M Dickerson ${ }^{4}$, Donald J DiPette ${ }^{1}$, Scott C Supowit ${ }^{1}$ and Gianfranco D Alpini ${ }^{1,5,6}$
}

The role of sensory innervation in the regulation of liver physiology and the pathogenesis of cholestatic liver disease are undefined. Biliary proliferation has been shown to be coordinately controlled by parasympathetic and sympathetic innervation of the liver. The aim of our study was to address the role of the sensory neuropeptide calcitonin gene-related peptide $(\alpha-C G R P)$ in the regulation of cholangiocyte proliferation during cholestasis induced by extrahepatic bile duct obstruction (BDL). Our study utilized a knockout (KO) mouse model, which lacks the sensory neuropeptide $\alpha$-CGRP. Wildtype (WT) and $\alpha$-CGRP KO mice were subjected to sham surgery or BDL for 3 and 7 days. In addition, immediately after $\mathrm{BDL}, \mathrm{WT}$ and $\mathrm{KO}$ mice were administered the CGRP receptor antagonist $\left(\mathrm{CGRP}_{8-37}\right)$ for 3 and 7 days by osmotic minipumps. Liver sections and isolated cholangiocytes were evaluated for proliferation markers. Isolated WT BDL ( 3 days) cholangiocytes were stimulated with $\alpha$ - and $\beta$-CGRP and evaluated for proliferation and CAMP-mediated signaling. Lack of $\alpha$-CGRP inhibits cholangiocyte proliferation induced by BDL at both 3 and 7 days. BDL-induced cholangiocyte proliferation in WT mice was associated with increases of circulating $\alpha$-CGRP levels. In vitro, $\alpha$ - and $\beta$-CGRP stimulated proliferation in purified BDL cholangiocytes, induced elevation of CAMP levels, and stimulated the activation of cAMPdependent protein kinase A and CAMP response element binding protein DNA binding. In conclusion, sensory innervation of the liver and biliary expression of $\alpha$-CGRP play an important role in the regulation of cholangiocyte proliferation during cholestasis.

Laboratory Investigation (2007) 87, 914-926; doi:10.1038/labinvest.3700602; published online 9 July 2007

KEYWORDS: cholestasis; intrahepatic biliary epithelium; CAMP; sensory innervation; protein kinase A

Cholangiocytes are the target cells in cholangiopathies including primary sclerosing cholangitis (PSC) and primary biliary cirrhosis (PBC). ${ }^{1}$ In rat models of experimental cholestasis including bile duct ligation (BDL), cholangiocyte proliferation is associated with enhanced intracellular cyclic adenosine $3^{\prime}, 5^{\prime}$-monophosphate (cAMP) levels., Cholangiocytes display neuroendocrine phenotypes during cholestatic liver diseases and secrete neural factors and respond to neuropeptides with alterations in proliferation. ${ }^{1,3-8}$ Interruption of parasympathetic and sympathetic innervation decreases cholangiocyte cAMP levels and proliferation, and induces biliary apoptosis in BDL rats. ${ }^{4,7}$ Administration of cAMP-agonists reverses the decrease in cholangiocyte proliferation and the increase in cholangiocyte apoptosis induced by parasympathetic and sympathetic denervation. ${ }^{4,7}$

In the liver, two afferent nerve pathways have been identified: the vagal afferent nerve pathway and the spinal afferent nerve pathway (which runs through the dorsal root ganglion, DRG). ${ }^{9}$ Sensory nerves also possess an efferent function that is mediated by the release of sensory neuropeptides (ie, $\alpha$-calcitonin gene-related peptide, $\alpha$-CGRP) from their peripheral terminals in tissues they innervate, regulating cellular functions independent of sensation. ${ }^{10}$ In rat and mouse liver, CGRPpositive innervation is present as dense networks in the fibromuscular layer of the biliary tree, surrounding the portal vein, and in the stromal compartment of portal areas. ${ }^{11,12}$ 
$\alpha$-CGRP is generated from the calcitonin gene transcript, which produces calcitonin in the thyroid $\mathrm{C}$ cells and $\alpha$-CGRP in the sensory neurons. ${ }^{13}$ The predominant site of $\alpha$-CGRP synthesis and storage is in the sensory neurons of the DRG, which terminate peripherally on tissues innervated by the sensory nervous system. ${ }^{14}$ Another isoform, $\beta$-CGRP, is generated from a separate gene. ${ }^{15} \beta$-CGRP differs from $\alpha$-CGRP by three amino acids in rats and one in humans. ${ }^{15}$ $\alpha$ - and $\beta$-CGRP are postulated to exert distinct hemodynamic and gastric effects in man, respectively. ${ }^{16}$

CGRP signals via the G-protein-coupled, calcitonin-like receptor (CLR). ${ }^{17}$ CLR requires a receptor activity-modifying protein (RAMP) to be functionally active. ${ }^{18}$ The RAMP family of proteins is comprised of three members: RAMP-1, -2 , and -3 . RAMP(s) function as accessory proteins that regulate the trafficking of CLR to the cell membrane and the pharmacological specificity of CLR. ${ }^{19}$ Both $\alpha$ - and $\beta$-CGRP signal through the CLR/RAMP1 receptor. ${ }^{19} \mathrm{~A}$ third protein, receptor component protein (RCP), ${ }^{20,21}$ is required for CLR signaling. RCP is an accessory protein required to couple the CLR/RAMP complex to intracellular signaling. ${ }^{20,21}$ Binding of CGRP to the CLR/RAMP1/RCP receptor complex leads to increased cAMP levels via $\mathrm{G} \alpha_{\mathrm{s}}$-dependent adenylyl cyclase activation resulting in activation of cAMP-dependent protein kinase $\mathrm{A}(\mathrm{PKA})$ and cAMP response element binding protein $(\mathrm{CREB}),{ }^{22,23}$ which is a key pathway stimulating cholangiocyte proliferation. ${ }^{24}$ The role of sensory innervation and neuropeptides in the regulation of cholangiocyte pathophysiology is unknown.

\section{MATERIALS AND METHODS Materials}

Reagents were purchased from Sigma Chemical Co. (St Louis, MO, USA) unless otherwise indicated. Rat $\alpha$ - and $\beta$-CGRP were purchased from Phoenix Pharmaceuticals, Inc. (Belmont, CA, USA). The antibody against proliferating cell nuclear antigen (PCNA) was purchased from Santa Cruz Biotechnology Inc. (Santa Cruz, CA, USA). The following antibodies were used for CGRP receptor protein immunohistochemistry in liver sections: (i) NY1024, a rabbit polyclonal antibody raised against the peptide CWNDVAAGTESMQ of mouse CLR; (ii) 1065, a chicken polyclonal antibody raised against the peptide EEQIEALLHTVT of mouse RCP; and (iii) RAMP 1 (Santa Cruz). The following antibodies were used for CGRP receptor protein immunoblotting in purified cholangiocytes: (i) NY1045, a rabbit polyclonal raised against the peptide LGVTRNKIMT of mouse CLR; (ii) NY1020 is a rabbit polyclonal raised against the peptide MVTACRDPDYGTL of mouse RAMP1, and (iii) NY1047 is a rabbit polyclonal raised against the peptide GPEDEQSKSTSND of mouse RCP. The mouse anti-cytokeratin-7 (CK-7) antibody (clone RCK105) was purchased from Caltag Laboratories Inc. (Burlingame, CA, USA). RIA kits for the determination of intracellular cAMP and D-myo-inositol 1,4,5-trisphosphate $\left(\mathrm{IP}_{3}\right)$ levels were purchased from GE Healthcare (Arlington Heights, IL, USA).

\section{Animal Models}

A $\alpha$-CGRP knockout (KO) mouse model (20-25 g) was used. This is a homozygous KO model on a C57BL/6 background. The mouse model lacking the $\alpha$-CGRP/CT gene was generated as described. ${ }^{25}$ In addition, age-matched male C57BL/6 (wild type, WT) mice were purchased from Charles River (Wilmington, MA, USA). Studies were performed in: (i) sham-operated (normal) mice and (ii) WT or $\alpha$-CGRP KO mice that (immediately after BDL) were treated with saline or the CGRP receptor antagonist, $\mathrm{CGRP}_{8-37}(0.55 \mathrm{mg} / \mathrm{kg}$ body weight/day by IP-implanted Alzet ${ }^{\mathbb{R}}$ minipumps $)^{26}$ for 3 or 7 days. BDL was performed as described. ${ }^{27}$ Study protocols were performed in compliance with the institutional guidelines.

\section{Cholangiocyte Isolation}

Isolated cholangiocytes (95-100\% pure by CK-7 immunohistochemistry) were obtained by immunoaffinity separation $^{24,28,29}$ with a monoclonal antibody, rat IgG2a (provided by Dr R Faris, Providence, RI, USA), against an antigen expressed by cholangiocytes. In vitro studies aimed to evaluate the effects of $\alpha$-CGRP or $\beta$-CGRP on signal transduction were performed in purified cholangiocytes from 3-day BDL mice.

\section{Analysis of $\alpha$-CGRP in Liver Sections}

Analysis of $\alpha$-CGRP expression was performed in frozen liver sections $(20 \mu \mathrm{m}$; three slides per treatment group) from normal and 3-day BDL WT and KO mice. Sections were defrosted at room temperature (RT) and fixed in $4 \%$ paraformaldehyde (in $1 \times$ phosphate-buffered saline, PBS), permeabilized in PBST $(1 \times$ PBS with $0.2 \%$ triton $)$, and blocked in $4 \%$ BSA (in PBST) for $1 \mathrm{~h}$ at RT. Primary antibodies for mouse anti-CK-7 (1:5) and rabbit anti- $\alpha$-CGRP (1:100) were diluted in $1 \%$ BSA (in PBST). Sections were incubated overnight at $4{ }^{\circ} \mathrm{C}$ and washed three times for 10 min each with $1 \times$ PBST at RT. Sections were incubated with secondary antibodies (Cy2 anti-mouse (1:50) and $\mathrm{Cy} 3$ anti-rabbit (1:50); Jackson Immunochemicals, West Grove, PA, USA) for $2 \mathrm{~h}$ at RT protected from light. Following incubation, the slides were washed in PBST at RT and cover-slipped with Antifade gold containing 4V,6-diamidino-2-phenylindole (DAPI) as a counterstain (Molecular Probes, Eugene, OR, USA). Images were visualized using an Olympus IX-71 (Tokyo, Japan) confocal microscope.

\section{$\alpha$-CGRP, $\beta$-CGRP, and CGRP Receptor Component Expression}

The expression of CGRP receptor components (CLR, RCP, and RAMP 1 ) and $\alpha$-CGRP and $\beta$-CGRP were evaluated by: (i) immunohistochemistry in paraffin-embedded liver sections ( $n=3$ per group, $5 \mu \mathrm{m}$ thick); (ii) immunoblots in 
protein $(40 \mu \mathrm{g})$ from whole cholangiocyte lysates; and (iii) mRNA expression by real-time PCR in total RNA $(0.75 \mu \mathrm{g})$ from cholangiocytes from WT and $\mathrm{KO}$ normal and 3-day $\mathrm{BDL}$ mice. Immunohistochemistry for the CGRP receptor proteins, CLR, RCP, and RAMP 1, in liver sections was performed as follows. After deparaffinization, endogenous peroxidase activity was quenched with methanol-peroxide solution $(0.3 \%$ hydrogen peroxide: $80 \%$ methanol solution, Santoku Chemical Industries, Tokyo, Japan). Sections were hydrated in graded alcohol and rinsed in $1 \times$ PBS, before applying the antibody specific for CGRP receptor proteins (1:400) or nonimmune serum at $4{ }^{\circ} \mathrm{C}$ overnight. Sections were rinsed with $1 \times$ PBS for $5 \mathrm{~min}$, and incubated with the appropriate secondary biotinylated antibodies (Nichirei, Tokyo, Japan), then developed with NovaRed (Vector Laboratories, Burlingame, CA, USA). The specimens were observed using optical microscopy (Nikon, Tokyo, Japan) equipped with CCD camera and digitizer (Nikon, Tokyo, Japan). Immunoblots were performed as described. ${ }^{24}$ Protein loading was normalized by immunoblots for $\beta$-actin. ${ }^{30}$ Images of the bands were obtained using a phospho-imager, Storm 860, Amersham Biosciences (Piscataway, NJ, USA) and subsequently densitometry was carried out using Scion Imaging Software (Frederick, MD, USA).

To evaluate the gene expression of $\alpha$-CGRP, $\beta$-CGRP, and CGRP receptor components (CLR, RCP and RAMP1) in cholangiocytes, we employed the $\mathrm{RT}^{2}$ Real-Time assay from SuperArray (Frederick, MD, USA). RNA was extracted with the RNeasy Mini Kit (Qiagen Inc., Valencia, CA, USA) and reverse transcribed using the Reaction Ready ${ }^{\mathrm{TM}}$ First Strand cDNA synthesis kit (SuperArray, Frederick, MD, USA). SYBR Green PCR master mix (SuperArray) was utilized in the experimental assay with $\mathrm{RT}^{2} \mathrm{PCR}$ rat primers designed specifically for $\alpha$-CGRP, $\beta$-CGRP, CLR, RCP and RAMP- 1 , and the housekeeping gene, glyceraldehyde-3-phosphate dehydrogenase (SuperArray, Frederick, MD, USA). Real-time RTPCR was performed with an ABI Prism 7900HT System using a two-step PCR cycling program at $95^{\circ} \mathrm{C}$ for $10 \mathrm{~min}$ followed by 40 cycles of $95^{\circ} \mathrm{C}$ for $15 \mathrm{~s}$ and $60^{\circ} \mathrm{C}$ for $1 \mathrm{~min}$. A $\Delta \Delta C_{\mathrm{t}}$ analysis was performed using normal WT cholangiocytes as the control.

\section{Histology, Immunohistochemical Staining, and Circulating CGRP Levels}

For in vivo studies, we measured plasma CGRP levels, liver weight, body weight and liver to body weight ratio, and lobular morphology, necrosis and the degree of portal inflammation from the selected groups of animals. Total plasma CGRP levels were measured with a commercial EIA kit (Peninsula Laboratories, San Carlos, CA, USA). Lobular morphology, necrosis, and the degree of portal inflammation were determined by H\&E staining of paraffin-embedded liver sections (three slides evaluated per group of animals, $4-5 \mu \mathrm{m}$ thick). At least 10 different portal areas were evaluated for each parameter. For quantification of damage, the following cate- gories were applied: 0 null; 1 limited to portal area; 2 intermediate; and 3 pan lobular. Liver sections were examined in a coded fashion by a microscope (Nikon, Tokyo, Japan) equipped with a camera. Apoptosis was evaluated by TUNEL analysis using a commercially available kit (Wako Chemicals, Tokyo, Japan). Sections were evaluated in a coded fashion using light microscopy (Nikon, Tokyo, Japan). In all, 200 cells per slide were counted in 10 nonoverlapping fields.

\section{Analysis of Cholangiocyte Proliferation}

Cholangiocyte proliferation was evaluated by measurement of the number of PCNA- and CK-7-positive cholangiocytes in liver sections, ${ }^{7,24,31,32}$ and PCNA protein expression ${ }^{7,31}$ in cholangiocytes from the selected group of animals. Sections were evaluated in a coded fashion using light microscopy (Nikon, Tokyo, Japan). Over 100 cholangiocytes were counted in three different fields for each group of animals.

\section{Intracellular Signaling Mechanisms}

The in vitro studies to evaluate the effects of $\alpha$-CGRP or $\beta$-CGRP on proliferation and signaling were performed in cholangiocytes from 3-day BDL WT mice. The concentration of $\alpha$-CGRP and $\beta$-CGRP $\left(10^{-9} \mathrm{M}\right)$ used to stimulate purified mouse BDL cholangiocytes was in the range of that used in other in vitro studies ${ }^{33,34}$ and was similar to the circulating levels (pM range) of CGRP found in humans, ${ }^{35}$ rats, ${ }^{34}$ and mice in present studies (Table 1). Following isolation, cholangiocytes were incubated at $37^{\circ} \mathrm{C}$ for $1 \mathrm{~h}$ to regenerate membrane proteins damaged by proteolytic treatment. ${ }^{36}$ Subsequently, we evaluated the in vitro effects of $\alpha$ - and $\beta$-CGRP $\left(10^{-9} \mathrm{M}, 37^{\circ} \mathrm{C}\right.$ for $\left.90 \mathrm{~min}\right)$ on PCNA protein expression in cholangiocytes from 3-day BDL WT mice. We evaluated the in vitro effects of $\alpha$ - and $\beta$-CGRP $\left(10^{-9} \mathrm{M}\right.$ at RT for $5 \mathrm{~min}$ ) on cAMP and $\mathrm{IP}_{3}$ levels of cholangiocytes from BDL mice by RIA kits. ${ }^{30}$ We measured the effects of $\alpha$ - and $\beta$-CGRP $\left(10^{-9} \mathrm{M}\right.$ at $37^{\circ} \mathrm{C}$ for $\left.90 \mathrm{~min}\right)$ on the activity of PKA in WT BDL mouse cholangiocytes with the PepTag assay for nonradioactive detection of PKA according to the manufacturer's protocol (Promega, Madison, WI, USA). ${ }^{24,37}$ Finally, we measured the effect of $\alpha$ - and $\beta$-CGRP $\left(10^{-9} \mathrm{M}\right.$ at $37^{\circ} \mathrm{C}$ for $90 \mathrm{~min}$ ) on the activity and phosphorylation of CREB in purified WT BDL cholangiocytes in the absence/ presence of pretreatment with H-89 (PKA inhibitor, $10 \mu \mathrm{M}) .^{38}$ Activation and phosphorylation of CREB were evaluated by a transcription factor assay kit (Active Motif, Carlsbad, CA, USA), which detects binding activity of phosphorylated CREB (Ser-133).

To evaluate whether CGRP secreted by cholangiocytes stimulates cholangiocyte proliferation by an autocrine mechanism, the supernatant of isolated cholangiocytes (after $6 \mathrm{~h}$ of incubation at $37^{\circ} \mathrm{C}$ ) from 3-day BDL WT and $\mathrm{KO}$ mice was transferred into plates containing our murine cholangiocyte cell line. ${ }^{39}$ In addition, our murine cholangiocyte cell line was also pretreated in vitro with the CGRP receptor antagonist $\left(\mathrm{CGRP}_{8-37}, 1 \mu \mathrm{M}\right)$ for 30 min prior to the addition 
Table 1 Serum CGRP levels, liver to body weight ratio, inflammation, necrosis, lobular damage, and cholangiocyte proliferation and apoptosis in wild-type and KO normal and 3-day BDL mice

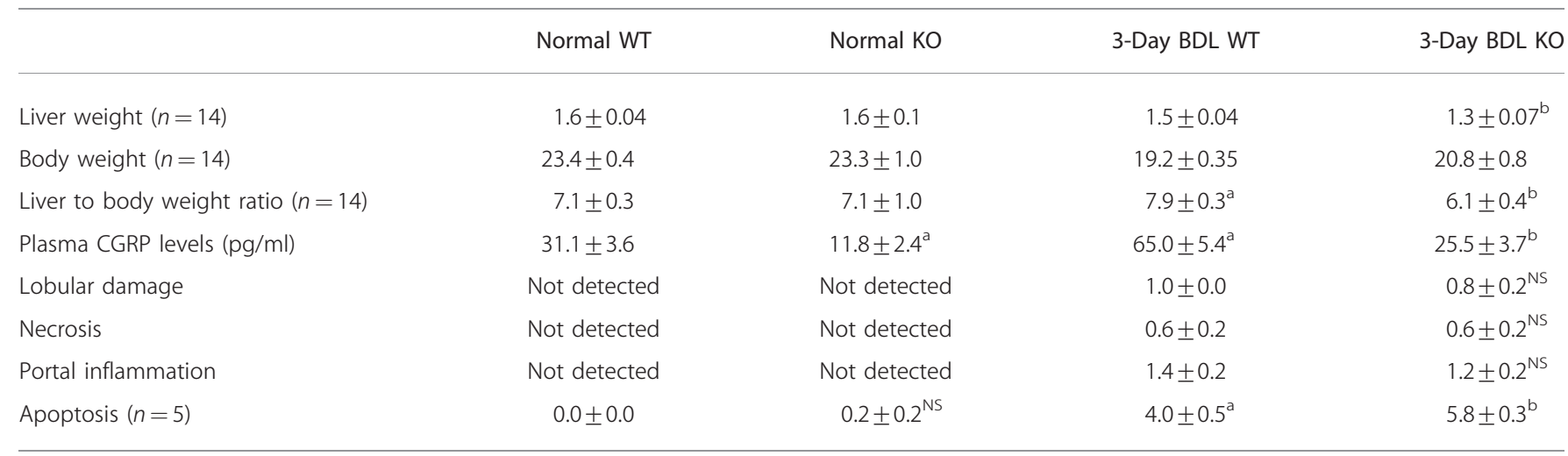

Data are mean \pm s.e.m. of cumulative values obtained from the evaluation of 10 portal tracts from three different slides for each group.

NS, not significant.

${ }^{\mathrm{a}} P<0.05$ vs WT normal mice.

${ }^{\mathrm{b}} P<0.05$ vs WT BDL mice.

of the supernatant from 3-day BDL WT mice. After $24 \mathrm{~h}$ of incubation, cholangiocyte proliferation was evaluated by 3-(4,5-dimethylthiazol-2-yl)-5-(3-carboxymethoxyphenyl)2-(4-sulfophenyl)-2H-tetrazolium, inner salt (MTS) proliferation assay. ${ }^{6,40}$ This is the same approach that we have used for evaluating the stimulatory effects of nerve growth factor (NGF, present in the supernatant of primary cultures of BDL cholangiocytes) on the proliferation of normal cholangiocytes. ${ }^{41}$

\section{Statistical Analysis}

All data are expressed as mean \pm s.e.m. Differences between groups were analyzed by the Student unpaired $t$-test when two groups were analyzed and analysis of variance (ANOVA) when more than two groups were analyzed, followed by an appropriate post hoc test.

\section{RESULTS}

\section{In Situ Localization of Intrahepatic $\alpha$-CGRP-Positive Sensory Innervation}

We performed immunofluorescence for CK-7 and CGRP in liver sections from normal and 3-day BDL WT and $\mathrm{KO}$ mice (Figure 1). Interestingly, in normal and BDL WT mice, there was colocalization of $\alpha$-CGRP in the areas stained positive for CK-7 (Figure 1). As expected, in the liver sections of normal and 3-day BDL KO mice, there was absence of $\alpha$-CGRPpositive staining in the liver sections (Figure 1).

\section{Cholangiocytes Express $\alpha$-CGRP, $\beta$-CGRP, and CGRP Receptor Components}

CGRP receptor proteins, CLR, RCP, and RAMP 1, were expressed by bile ducts from normal WT and $\mathrm{KO}$ mice and 3-day BDL WT and KO mice as shown by immunohistochemistry in liver sections and by immunoblotting in isolated cholangiocytes (Figure 2a and b). Immunoblotting analysis shows that protein expression for CLR, RCP, and RAMP1 are not significantly different in cholangiocytes from the four groups of animals (Figure 2b). Bile ducts and isolated cholangiocytes also expressed RAMPs 2 and 3 by immunohistochemistry (not shown).

Both normal and BDL WT cholangiocytes expressed the message for $\alpha$-CGRP. The message for $\alpha$-CGRP was upregulated (four-fold) compared to normal WT cholangiocytes (Figure 3a). Cholangiocytes from normal and BDL KO mice did not express $\alpha$-CGRP mRNA (Figure 3a). $\beta$-CGRP expression was detected in normal WT cholangiocytes and almost not detectable in BDL WT and normal KO cholangiocytes (Figure 3a). However, there was an unexpected 10 -fold increase in $\beta$-CGRP mRNA in cholangiocytes from BDL KO mice (Figure 3a). Real-time RT-PCR revealed CLR mRNA expression in normal WT and KO cholangiocytes and an approximately 167-fold increase in the message for CLR in cholangiocytes from BDL WT mice compared to normal WT (Figure 3b). In comparison, a 62-fold increase in the expression of CLR mRNA was observed in BDL KO cholangiocytes, which indicates a significant reduction in the expression of CLR in BDL KO compared to BDL WT cholangiocytes (Figure 3b). Low levels of the RCP and RAMP 1, which are required for the function of CLR, were detected in both normal WT and KO cholangiocytes (Figure 3b). However, the mRNA expression levels of RCP and RAMP 1 were significantly upregulated in both BDL WT and KO mice (Figure $3 \mathrm{~b}$ ). Although we found changes in the CGRP receptor expression at the mRNA level, the changes observed at the message level did not result in significant alterations of expression at the protein level, which may be due to a number of post-transcriptional factors such as message instability. 

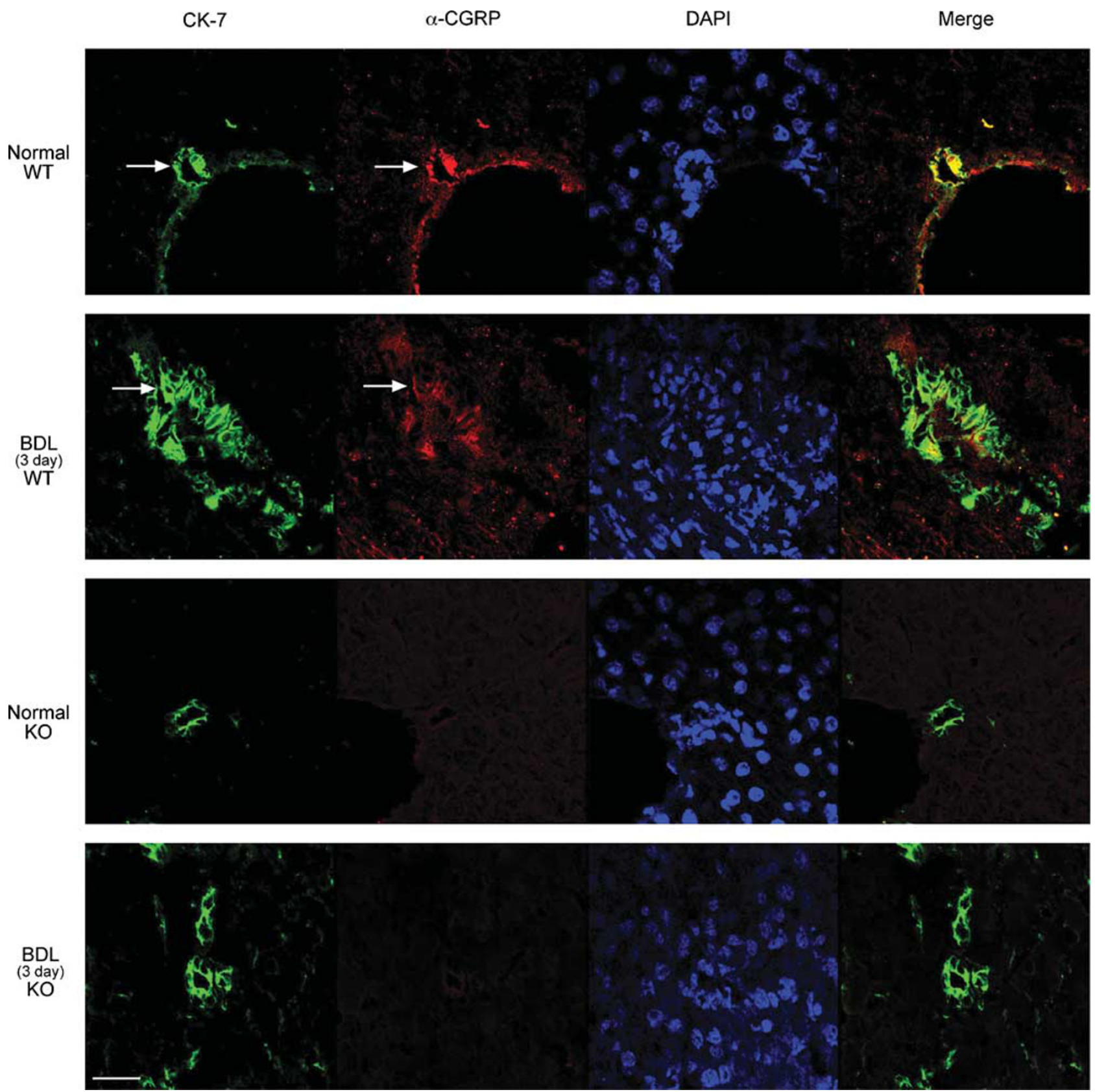

Figure 1 Localization of $\alpha$-CGRP (red) by immunofluorescence in normal and 3-day BDL WT mice liver sections. Bile ducts were stained with CK-7 (green). $\alpha$-CGRP-positive staining and CK-7 colocalize in the bile ducts of 3-day BDL WT mice. The scale bar represents $20 \mu \mathrm{M}$. Arrows indicate bile ducts.

\section{Histology and Liver Weight to Body Weight Ratios}

No significant differences in body weight were observed in normal and BDL KO mice compared with their corresponding normal and 3-day BDL WT mice (Table 1). Consistent with the finding that the lack of $\alpha$-CGRP induces a decrease in bile duct mass, in KO BDL mice, there was a significant decrease in both liver weight and liver to body weight ratio compared to 3-day BDL WT mice (Table 1). There were no significant differences in the degree of portal inflammation, necrosis, and lobular damage among the selected groups of animals (Table 1).

\section{Lack of $\alpha$-CGRP Reduces Biliary Proliferation During Cholestasis}

Consistent with previous findings, ${ }^{42}$ there was a significant increase in biliary proliferation in both 3- and 7-day BDL WT mice compared to normal WT mice (Figure 4a and Table 2). In liver sections from 3- and 7-day BDL KO mice, we observed a reduction in the number of PCNA- and CK-7positive cholangiocytes compared to 3- and 7-day BDL WT mice (Figure 4a and Table 2). No significant differences were noted for the WT and KO normal mice treatment groups with respect to cholangiocyte proliferation and intrahepatic 
a

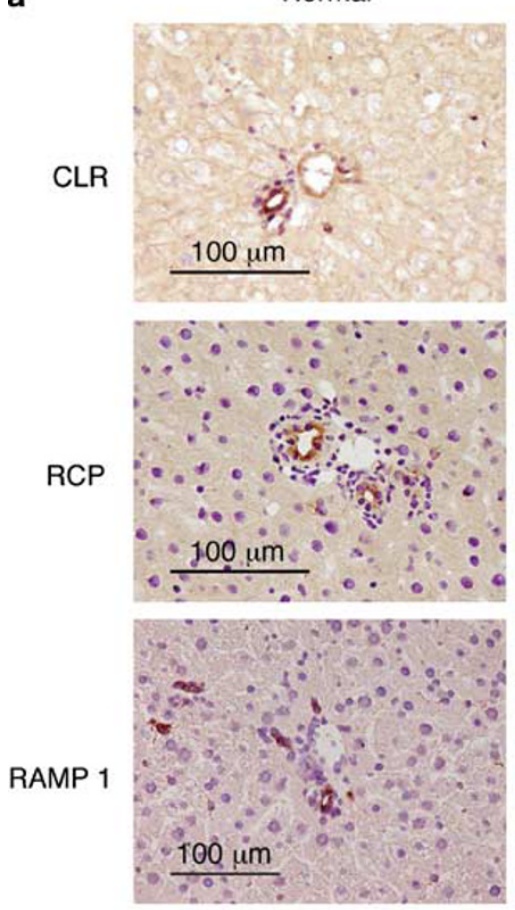

BDL

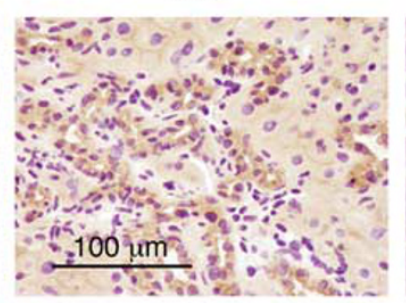

Normal KO
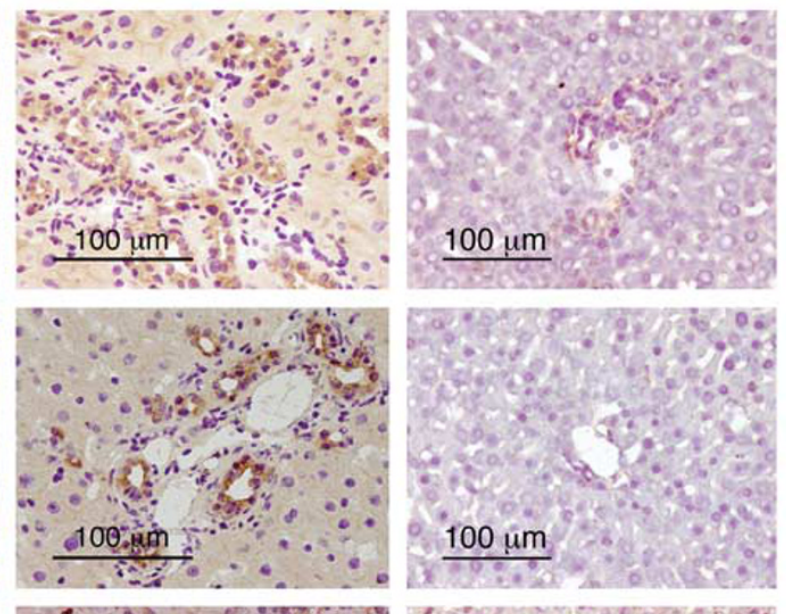
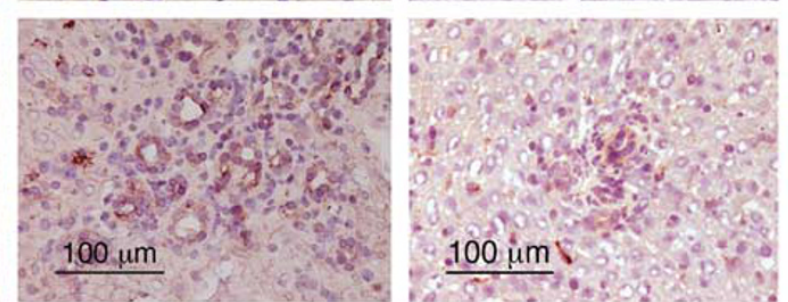

BDL KO
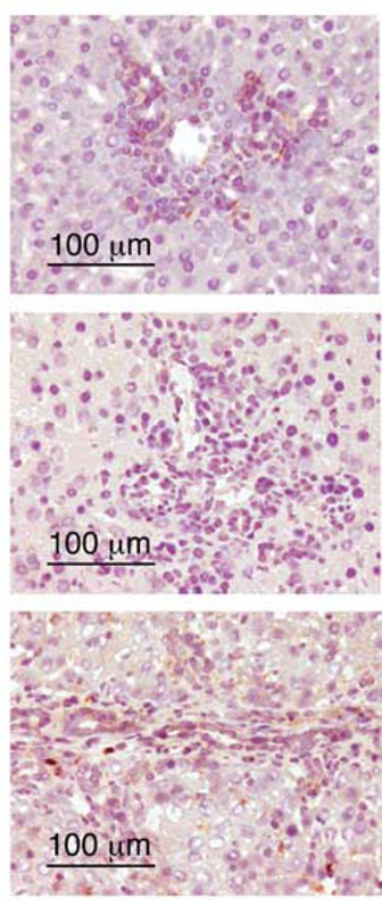

b
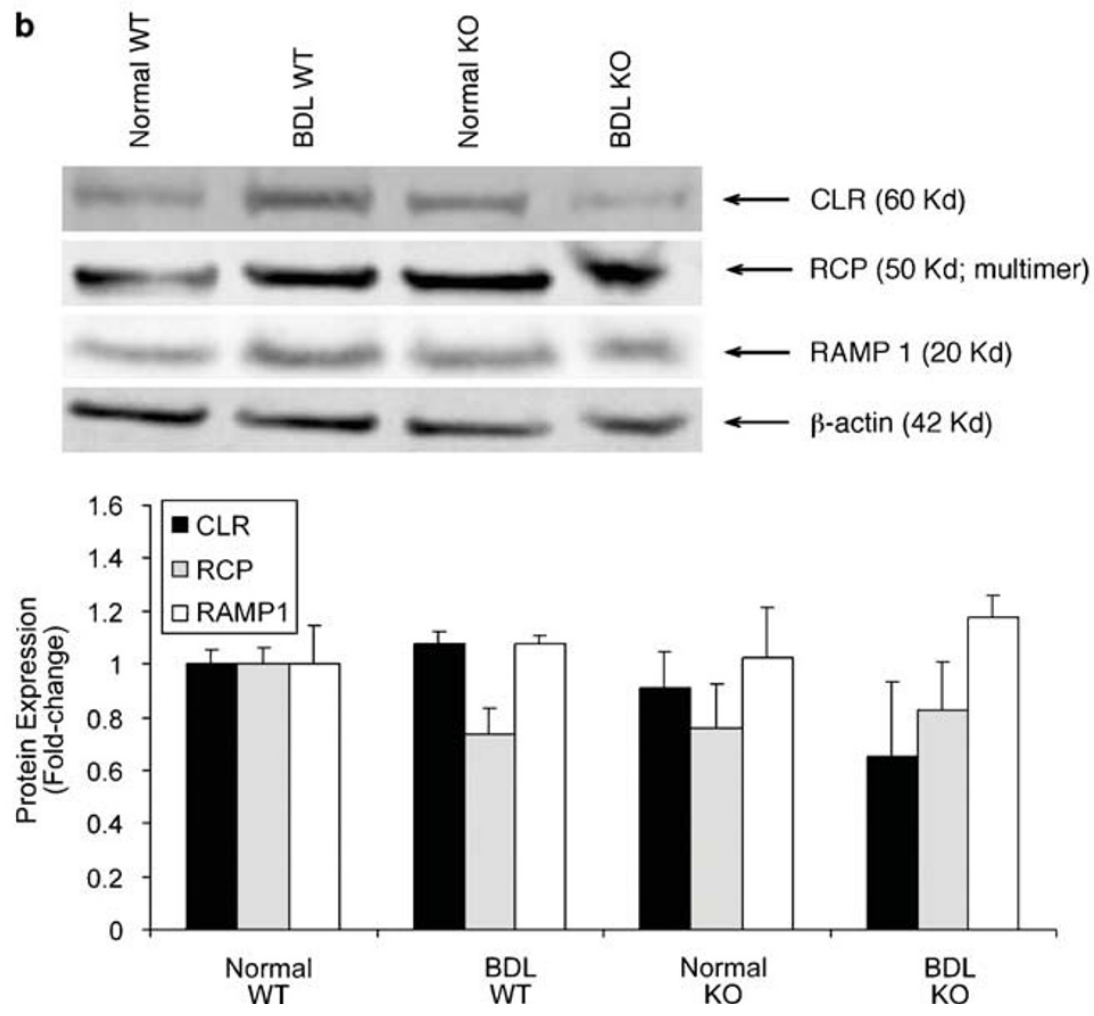

Figure 2 (a) The CGRP receptor components, CLR, RCP, and RAMP 1, were expressed by bile ducts from normal and 3-day BDL WT and KO mice by immunohistochemistry. Original magnification, $\times 20$. (b) By immunoblotting, CGRP receptor components were expressed by purified cholangiocytes from normal and 3-day BDL WT and KO mice. Immunoblotting analysis shows that protein expression for CLR, RCP, and RAMP1 remains relatively constant with no significant changes in purified cholangiocytes from the four groups of animals. Representative blots are shown. Data are mean \pm s.e.m. of $n=3$ experiments.

biliary mass (Figure $4 \mathrm{a}$ and Table 2). We found that the administration of $\mathrm{CGRP}_{8-37}$ to both 3- and 7-day BDL WT mice reduced the number of PCNA- and CK-7-positive cholangiocytes compared to 3- and 7-day BDL WT mice, respectively (Table 2). The administration of $\mathrm{CGRP}_{8-37}$ to $\alpha$-CGRP KO BDL mice that blocked $\beta$-CGRP in these mice: 

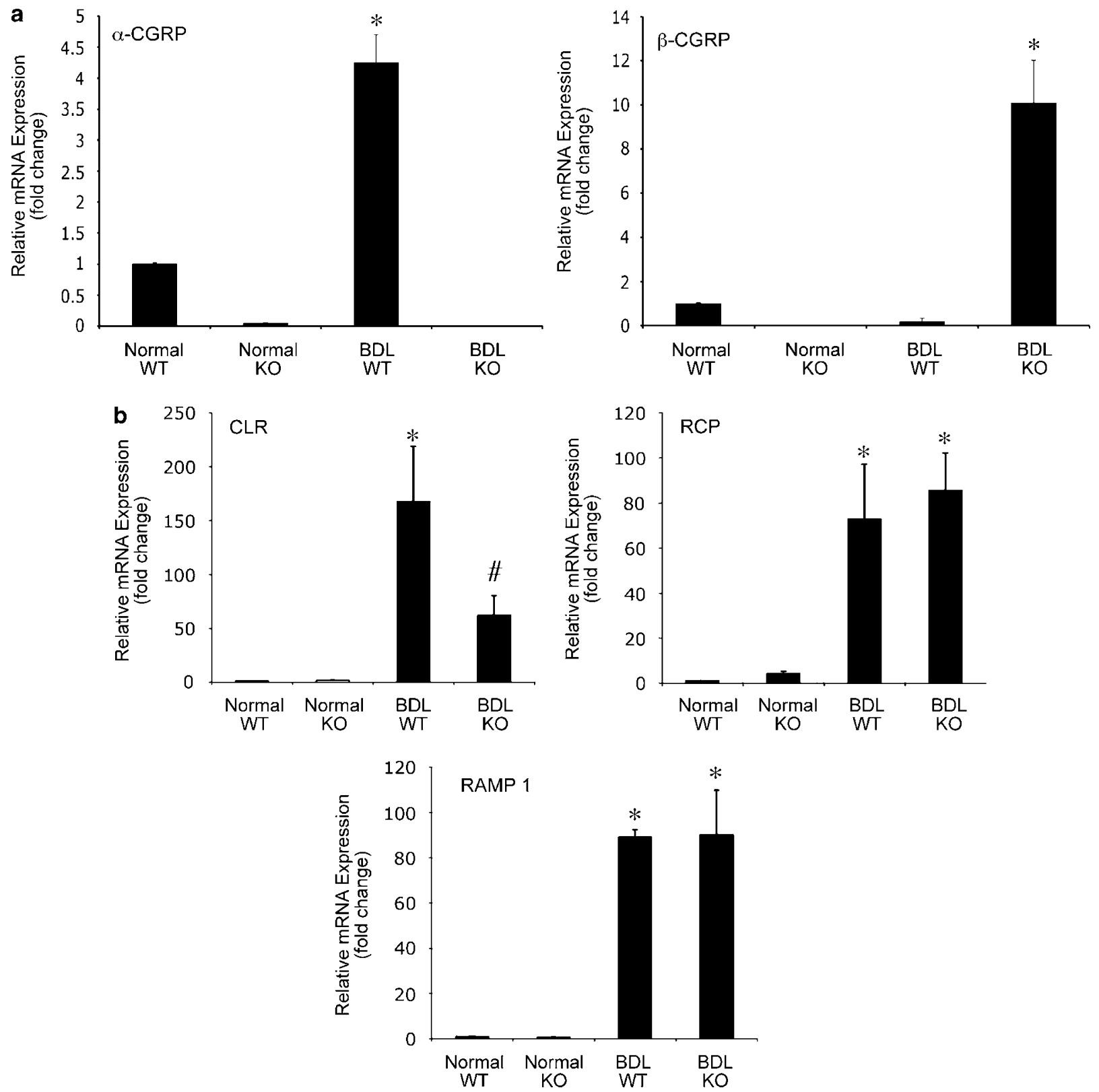

Figure 3 (a) The message for $\alpha$-CGRP was expressed in normal and BDL WT cholangiocytes with a significant increase observed in BDL WT. There was also a significant increase in the $\beta$-CGRP message in BDL KO cholangiocytes. (b) Cholangiocytes isolated from normal and BDL WT and KO mice express mRNA for CGRP receptor components, CLR, RCP, and RAMP1. Upregulation of receptor expression was observed in BDL WT and KO mice. Data are mean \pm s.e.m. of $n=3$ experiments. ${ }^{*} P<0.05$ vs normal WT. ${ }^{\#} P<0.05$ vs BDL WT.

(i) further reduced the number of PCNA-positive cholangiocytes in 3- and 7-day $\alpha$-CGRP KO BDL mice and (ii) decreased the number of CK-7-positive cholangiocytes in 7-day $\alpha$-CGRP KO BDL mice (Table 2).

In 3-day BDL KO mice, there was a concomitant increase in the number of apoptotic cholangiocytes compared to the degree of cholangiocyte apoptosis observed in 3-day BDL WT mice (Table 1). No difference in cholangiocyte apoptosis was seen between WT and KO normal mice (Table 1). Similarly, there was decreased PCNA protein expression in cholangio- cytes from 3-day BDL KO mice compared with cholangiocytes from BDL WT mice (Figure 4b).

\section{Cholestasis Induced by BDL Elevates Circulating CGRP Levels}

Consistent with previous studies demonstrating that circulating total CGRP levels are elevated in cirrhosis, ${ }^{43,44}$ we found a two-fold increase in plasma CGRP levels in 3-day BDL WT mice compared to normal WT mice (Table 1). As expected, we found that total circulating levels of CGRP were 
a
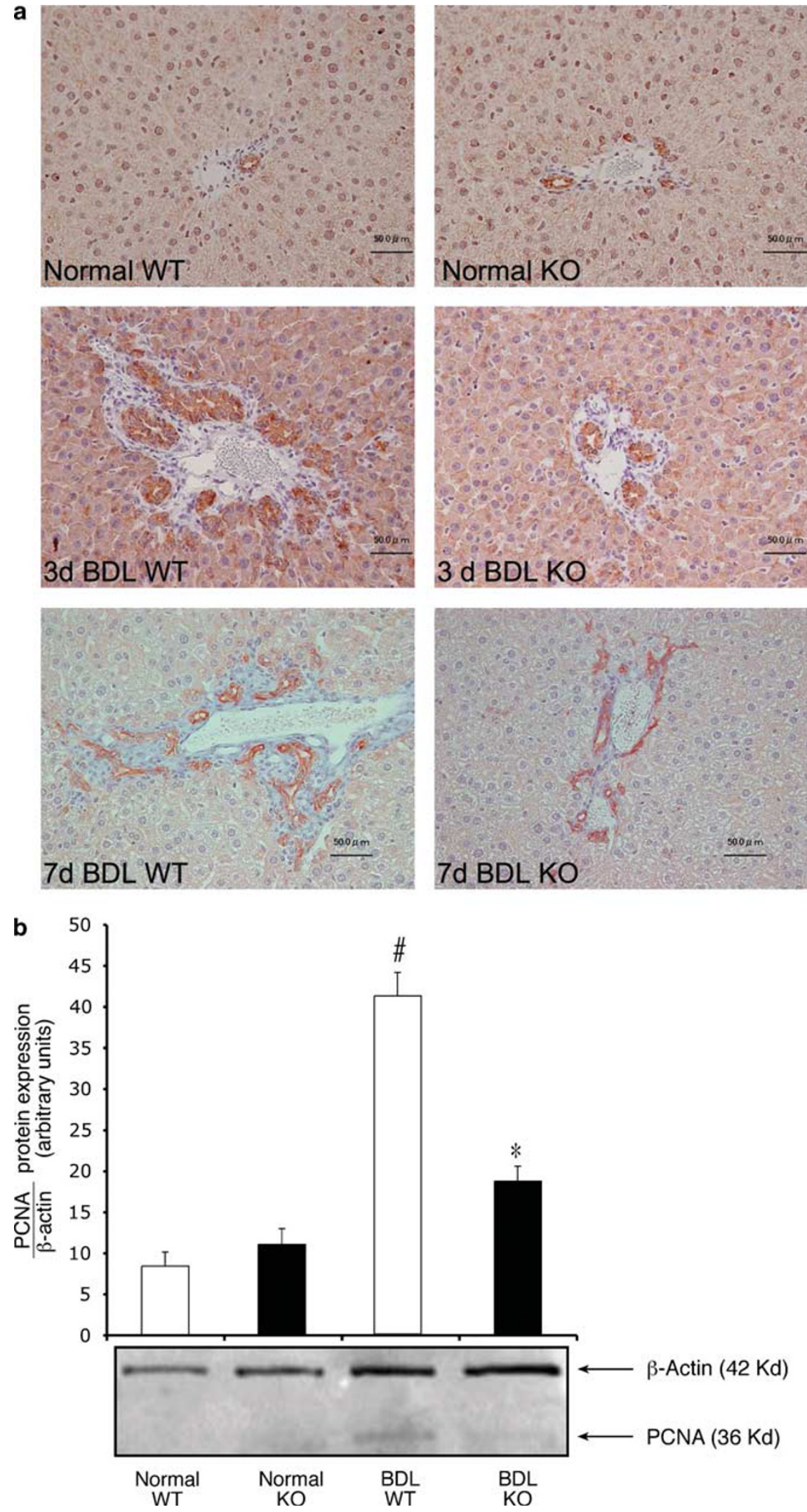

Figure 4 (a) The number of CK-7-positive cholangiocytes in liver sections from 3- and 7-day KO BDL mice was reduced compared to 3- and 7-day WT BDL mice. Data are mean \pm s.e.m. of $n=5$ experiments. (b) PCNA protein expression in purified cholangiocytes from 3-day KO BDL mice was reduced compared with cholangiocytes from 3-day WT BDL mice. Data are mean + s.e.m. of eight experiments. ${ }^{\#} P<0.05$ vs normal WT. ${ }^{*} P<0.05$ vs BDL WT. 
Table 2 Measurement of the number of PCNA- and CK-7positive cholangiocytes in: (i) WT and $\alpha$-CGRP KO normal mice and (ii) WT and $\alpha$-CGRP KO mice that (immediately after BDL) were treated with saline or the CGRP receptor antagonist, CGRP $_{8-37}$ for 3 or 7 days

PCNA-positive cholangio- CK-7-positive cholangiocytes $(n=5) \quad$ cytes $(n=5)$

\begin{tabular}{|c|c|c|}
\hline Normal WT & $0.4 \pm 0.2$ & $16.3 \pm 01.6$ \\
\hline Normal KO & $0.2 \pm 0.2^{\mathrm{NS}}$ & $17.2 \pm 0.7^{\mathrm{NS}}$ \\
\hline BDL WT+saline & $21.4 \pm 1.2^{*}$ & $77.7 \pm 2.3^{*}$ \\
\hline \multicolumn{3}{|l|}{3 days } \\
\hline $\mathrm{BDL} W T+\mathrm{CGRP}_{8-37}$ & $11.0 \pm 1.2^{\mathrm{a}}$ & $53.8 \pm 1.8^{\mathrm{a}}$ \\
\hline \multicolumn{3}{|l|}{3 days } \\
\hline BDL KO+saline & $12.6 \pm 1.0^{\mathrm{a}}$ & $45.0 \pm 1.4^{\mathrm{a}}$ \\
\hline \multicolumn{3}{|l|}{3 days } \\
\hline $\mathrm{BDL} \mathrm{KO}+\mathrm{CGRP}_{8-37}$ & $7.7 \pm 0.7^{\mathrm{a}}$ & $43.6 \pm 2.3^{a}$ \\
\hline \multicolumn{3}{|l|}{3 days } \\
\hline BDL WT+saline & $43.0 \pm 2.5^{*, b}$ & $92.6 \pm 3.5^{*, b}$ \\
\hline \multicolumn{3}{|l|}{7 days } \\
\hline $\mathrm{BDL} W T+\mathrm{CGRP}_{8-37}$ & $25.0 \pm 2.0^{c}$ & $70.4 \pm 1.7^{c}$ \\
\hline \multicolumn{3}{|l|}{7 days } \\
\hline BDL KO+saline & $28.4 \pm 2.3^{c}$ & $61.2 \pm 2.6^{c}$ \\
\hline \multicolumn{3}{|l|}{7 days } \\
\hline $\mathrm{BDL} \mathrm{KO}+\mathrm{CGRP}_{8-37}$ & $19.4 \pm 1.4^{c}$ & $53.2 \pm 2.1^{c}$ \\
\hline 7 days & & \\
\hline
\end{tabular}

Data are mean \pm s.e.m. of cumulative values obtained from the evaluation of 10 portal tracts from three different slides for each group.

NS, not significant.

${ }^{*} P<0.05$ vs WT normal mice.

${ }^{\mathrm{a}} P<0.05$ vs WT 3 days BDL mice.

${ }^{\mathrm{b}} P<0.05$ vs WT 3 and 7 days BDL mice.

${ }^{\mathrm{c}} P<0.05$ vs WT 7 days BDL mice.

approximately 2.6 -fold lower in normal $\mathrm{KO}$ mice compared to normal WT mice (Table 1). Interestingly, we found that there was a slight but significant elevation in plasma CGRP levels in 3-day BDL KO mice compared to 3-day BDL WT mice (Table 1).

\section{$\alpha$ - and $\beta$-CGRP Stimulates Proliferation and Activates CAMP/PKA/CREB-Dependent Signaling}

We evaluated the effects of both $\alpha$ - and $\beta$-CGRP on the proliferation of cholangiocytes from 3-day BDL WT mice. In cholangiocytes from BDL WT, $\alpha$ - and $\beta$-CGRP also stimulated a 1.5- and 1.4-fold increase in PCNA protein expression, respectively. $\alpha$ - and $\beta$-CGRP significantly increased cAMP (but not $\mathrm{IP}_{3}$ ) levels of purified BDL cholangiocytes (Figure 5a). $\alpha$ - and $\beta$-CGRP also significantly increased the activity of PKA (Figure 5b) and DNA-binding activity of pCREB (Ser-133) (Figure 5c). The $\alpha$ - and $\beta$-CGRP-induced increase in pCREB DNA-binding activity was blocked by H-89 (Figure 5c).

\section{BDL Cholangiocyte Supernatant Stimulates the Proliferation of Murine Cholangiocytes}

We found that the supernatant from 3-day BDL WT cholangiocytes stimulated the proliferation of the murine cholangiocyte cell line ${ }^{39}$ compared to basal unstimulated cholangiocytes (Figure 6). In addition, the supernatant from 3-day BDL KO cholangiocytes had no significant effect on cholangiocyte proliferation (Figure 6). Also, we found that in vitro pretreatment of the murine cholangiocyte cell line with $\mathrm{CGRP}_{8-37}$, prior to stimulation with 3-day BDL cholangiocyte supernatant, resulted in a reduction of cholangiocyte proliferation to near basal levels (Figure 6).

\section{DISCUSSION}

Studies have shown that circulating levels of sensory neuropeptides such as CGRP, ${ }^{43,44}$ substance $\mathrm{P}^{45}$ and adrenomedullin $^{46}$ are elevated in human and animal models of cirrhosis. Elevations of circulating neuropeptides have been shown to alter systemic and splanchnic circulation in patients with chronic liver diseases. ${ }^{47}$ The mechanisms regulating these events and the potential effects on cholangiocytes are not well defined. In our study, we present evidence that the sensory neuropeptide, $\alpha$-CGRP, plays a key role in the regulation of biliary mass during extrahepatic cholestasis.

The presence of $\alpha$-CGRP-positive sensory innervation of the vascular and biliary system of the liver suggests that these nerves play a key role in regulating biliary activity as well as hemodynamic functions. ${ }^{11,48}$ The presence of $\alpha$-CGRP immunoreactivity in bile ducts and the upregulation of $\alpha$-CGRP and CGRP receptor gene expression in isolated BDL WT cholangiocytes suggests the possibility of an autocrine signaling mechanism, which is activated by cholestasis and contributes to the proliferation of cholangiocytes similar to what we have previously described for vascular endothelial growth factor and NGF. ${ }^{31,41}$ In support of this concept, our data demonstrate that: (i) the supernatant (containing CGRP) from isolated 3-day BDL cholangiocytes stimulates the proliferation of mouse cholangiocytes in vitro and (ii) CGRP-induced in vitro increase in cholangiocyte proliferation is blocked by preincubation with $\mathrm{CGRP}_{8-37}$, suggesting that an autocrine (in addition to a paracrine pathway) signaling mechanism may exist. This finding is also evident in the lack of proliferation observed when mouse cholangiocytes were stimulated in vitro with the supernatant from 3-day BDL KO mice.

Along this line, we demonstrated that bile ducts express the receptor components required for CGRP signaling and that the lack of the sensory neuropeptide, $\alpha$-CGRP, significantly reduced biliary proliferation in a mouse model of extrahepatic cholestasis. Mice lacking $\alpha$-CGRP during cholestasis exhibited a decrease in cholangiocyte proliferation compared to 3- and 7-day BDL WT mice. Similarly, we found 

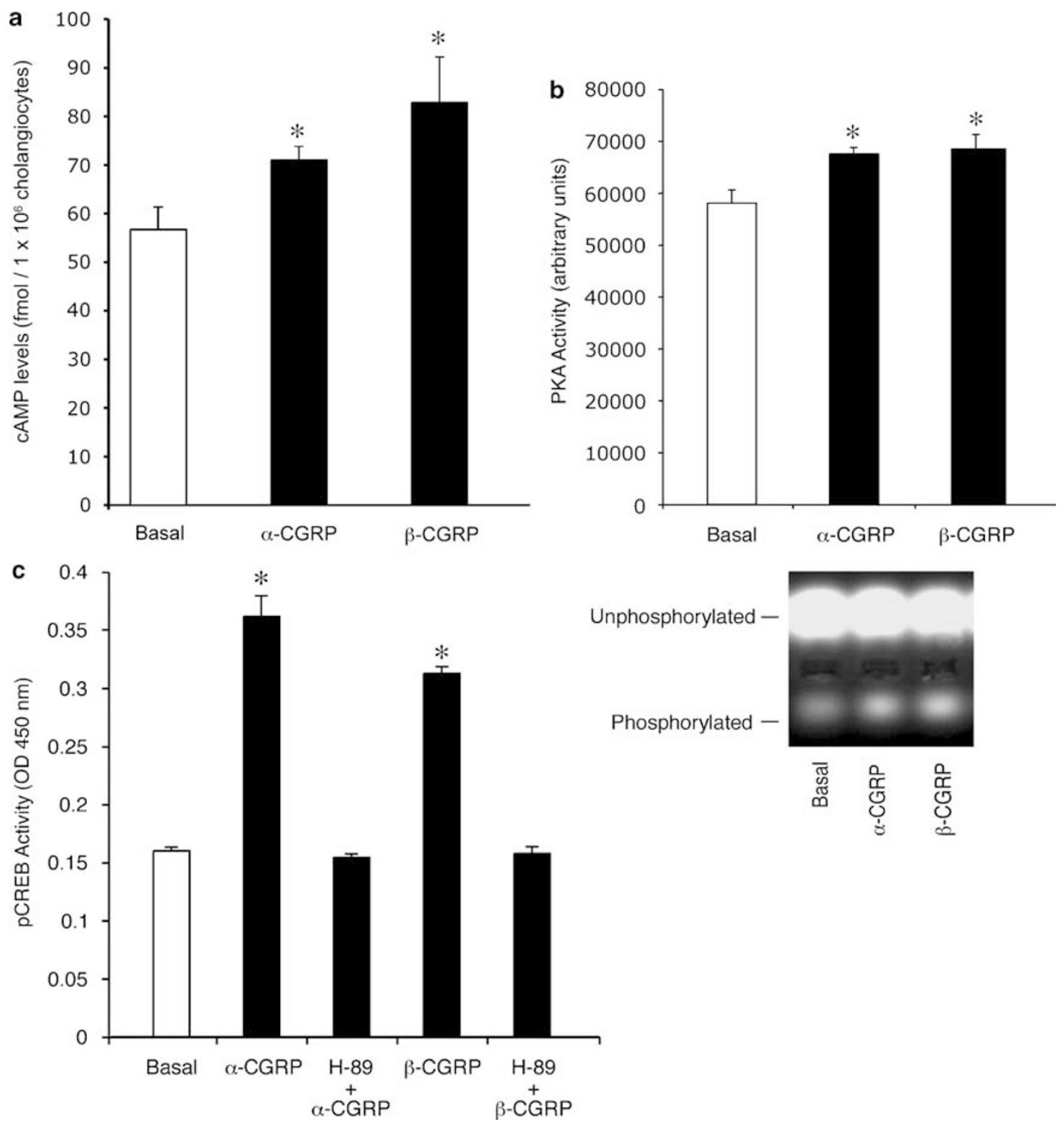

Figure $5 \alpha$ - and $\beta$-CGRP induced an increase in CAMP levels (a), the activity of PKA (b), and the binding activity of pCREB (Ser-133), which was blocked by $\mathrm{H}-89$ (c). Data are mean \pm s.e.m. of $3-6$ experiments. ${ }^{*} P<0.05$ vs basal.

that chronic administration of $\mathrm{CGRP}_{8-37}$ to $\mathrm{BDL}$ WT mice also resulted in decreased cholangiocyte proliferation, which would indicate an important role for the sensory neuropeptides $\alpha$ - and $\beta$-CGRP. To date, a double knockout model for $\alpha$ - and $\beta$-CGRP does not exist. To further clarify the role of $\beta$-CGRP in the regulation of cholangiocyte proliferation, we also evaluated the effects of chronic administration of $\mathrm{CGRP}_{8-37}$ (that also blocks $\beta$-CGRP) to BDL KO mice. We found that administration of $\mathrm{CGRP}_{8-37}$ reduced proliferation of cholangiocytes slightly below the levels of that observed for $\mathrm{BDL}$ KO mice, a finding that suggests that $\beta$-CGRP may have a minor role in the regulation of cholangiocyte proliferation. The observation that the administration of $\mathrm{CGRP}_{8-37}$ to 3-day KO BDL mice decreased the number of PCNA-positive cholangiocytes but not ductal mass (as shown by CK-7, compared to 3-day KO BDL mice) may be explained by a simple lag in timing between the two phenomena. Changes in gene expression that ultimately result in changes in cholangiocyte proliferation has a different temporal profile to the resulting changes in ductal mass containing well-differentiated, hormone-responsive bile ducts. We believe that at day 3 of BDL, the cholangiocytes have increased the expression of the machinery required to stimulate proliferation (e.g., PCNA), but that perhaps at this time point it is too premature to see a marked difference in cholangiocyte number. Whereas, at a later time point of 7 days, there has been sufficient time for the changes in PCNA expression to translate into changes in ductal mass. These findings are in 


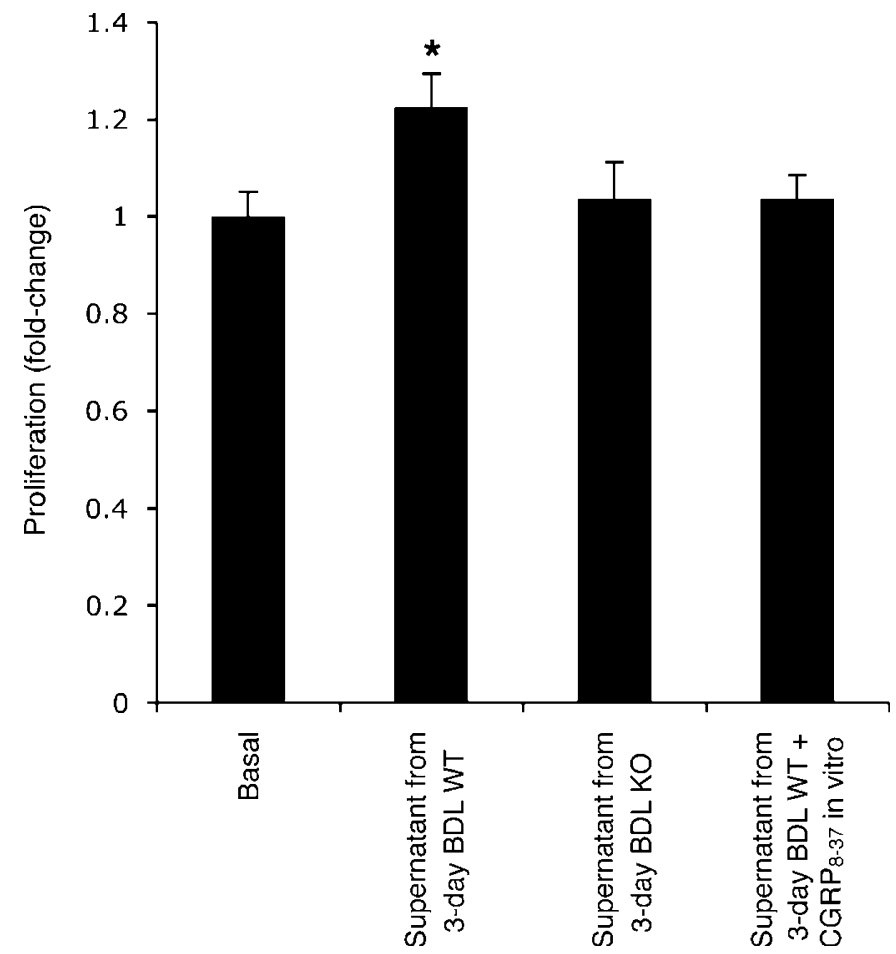

Figure 6 Effect of the supernatant of isolated cholangiocytes (after $6 \mathrm{~h}$ of incubation at $37^{\circ} \mathrm{C}$ ) from 3-day BDL WT and KO mice on the proliferation of mouse cholangiocyte cell lines. The mouse cholangiocyte cell line was also pretreated in vitro with the CGRP receptor antagonist (CGRP 8 -37, $1 \mu \mathrm{M}$ ) for 30 min prior to the addition of the supernatant from 3-day BDL WT mice. After $24 \mathrm{~h}$ of incubation, cholangiocyte proliferation was measured by MTS proliferation assay. We found that supernatant from 3-day BDL WT mice stimulates the proliferation of cholangiocytes compared to basal proliferative rates. Consistent with our in vivo data, supernatant from BDL KO mice did not significantly stimulate proliferation. Indeed, the stimulation of cholangiocyte proliferation by BDL WT mouse supernatant was blocked by in vitro pretreatment with $\mathrm{CGRP}_{8-37}$. Data are mean \pm s.e.m. of seven experiments. ${ }^{*} P<0.05$ vs basal.

agreement with our previous studies showing that: (i) rat bile ducts at day 3 of BDL respond minimally to secretin ${ }^{49}$ and (ii) secretin-stimulated bicarbonate-rich choleresis is evident at day 7 of BDL. ${ }^{49}$

We demonstrated, in isolated BDL WT cholangiocytes, that both $\alpha$-CGRP and $\beta$-CGRP stimulate the activation of a cAMP/PKA/CREB-dependent pathway. The findings that: (i) both $\alpha$ - and $\beta$-CGRP stimulated the same signaling mechanism; (ii) $\beta$-CGRP gene expression levels were elevated in BDL KO cholangiocytes; and (iii) other sensory neuropeptides, such as substance $\mathrm{P}^{45}$ and adrenomedullin, ${ }^{46}$ are elevated during chronic liver diseases providing an explanation for our observation of a significant but not a complete blockage of biliary proliferation during cholestasis in mice lacking $\alpha$-CGRP. However, the extent of reduction of intrahepatic ductal mass observed in $\alpha$-CGRP KO mice following BDL was similar to that observed in other studies. ${ }^{31,50,51}$ For example, biliary proliferation induced by BDL can be partially blocked by chronic administration of gastrin via osmotic minipumps, immunoneutralization of VEGF via administration of anti-VEGF, and during ischemia induced by hepatic artery ligation. ${ }^{31,50,51}$ In support of the concept that in addition to CGRP, other sensory neuropeptides regulates ductal mass, we have demonstrated that the sensory neuropeptide substance $\mathrm{P}$ also plays an important role in the regulation of biliary growth during BDL. We have found in $\mathrm{KO}$ mice lacking the $\mathrm{NK}_{1}$ receptor (ie, substance $\mathrm{P}$ receptor) a similar reduction in biliary proliferation during cholestasis as that observed in $\alpha$-CGRP KO mice, which indicates that both sensory neuropeptides, $\alpha$-CGRP and substance $\mathrm{P}$, play a coordinated role in the regulation of cholangiocyte proliferation during cholestasis. ${ }^{52}$ Thus, the fact that a number of sensory neuropeptides coordinately regulate ductal mass provides the explanation for the partial block of proliferation observed in BDL $\alpha$-CGRP KO mice. The upregulation of $\alpha$-CGRP expression in cholangiocytes during cholestasis and the significant reduction in biliary proliferation in mice lacking $\alpha$-CGRP attest to the importance of $\alpha$-CGRP-sensory innervation in the regulation of cholangiocyte proliferation during cholestasis. This finding is supported by previous studies demonstrating that sensory neurons and enteric neurons preferentially express $\alpha$-CGRP and $\beta$-CGRP, respectively. ${ }^{53}$

We found that supernatant from 3-day BDL WT mice stimulates the proliferation of cholangiocytes compared to their basal proliferative rates. Consistent with our in vivo data, supernatant from BDL KO mice did not significantly stimulate proliferation. Indeed, the stimulation of cholangiocyte proliferation by BDL WT mouse supernatant was blocked by in vitro pretreatment with $\mathrm{CGRP}_{8-37}$. These 
findings suggest that cholangiocyte proliferation is controlled at least in part by an autocrine mechanism in addition to paracrine signaling via sensory neurons.

We found that cholestasis induced by extrahepatic bile duct obstruction for 3 days stimulated a two-fold increase in total CGRP plasma levels. It is not known if the exact mechanism controlling the increase of plasma CGRP levels is due to a direct effect of BDL or an indirect compensatory mechanism. Future studies will be aimed to address if increased circulating bile acid levels during cholestasis have a direct effect on CGRP release from sensory neurons. We also noted a slight increase in total CGRP plasma levels in BDL $\mathrm{KO}$ mice, which may be due to a compensatory increase of $\beta$-CGRP expression in enteric neurons and/or lack of $\beta$-CGRP degradation due to cholestasis. The significant reduction in biliary mass in BDL KO mice suggests that $\alpha$-CGRP has a predominant role in the regulation of cholangiocyte proliferation during cholestasis. Regulation of sensory neuropeptide levels and blockage of signaling by antagonists may represent a potential treatment for cholestatic liver diseases.

\section{ACKNOWLEDGEMENTS}

We acknowledge Bryan Moss of the Scott \& White Hospital, Medical Illustration Department, for his assistance with figures and the Scott \& White Hospital animal facility staff assistance with animal surgical models. This work was supported by a grant award (\#060483) to Dr Glaser from Scott \& White Hospital; by the Dr Nicholas C Hightower Centennial Chair of Gastroenterology to Dr Alpini from Scott \& White Hospital, a VA Research Scholar Award, a VA Merit Award, and the NIH grant DK062975 to Dr Alpini; by a grant from Health and Labor Sciences Research Grants for the Research on Measures for Intractable Diseases (from the Ministry of Health, Labor and Welfare of Japan) and from Grant-in Aid for-Scientific Research C (16590573) from JSPS to Dr Ueno; and by an NIH grant DK052328 to Dr Dickerson.

1. Alvaro D, Mancino MG, Glaser S, et al. Proliferating cholangiocytes: a neuroendocrine compartment in the diseased liver. Gastroenterology 2007;132:415-431.

2. Alpini G, Glaser S, Ueno $Y$, et al. Heterogeneity of the proliferative capacity of rat cholangiocytes after bile duct ligation. Am J Physiol Gastrointest Liver Physiol 1998;274:G767-G775.

3. Fabris L, Strazzabosco M, Crosby HA, et al. Characterization and isolation of ductular cells coexpressing neural cell adhesion molecule and $\mathrm{BCl}-2$ from primary cholangiopathies and ductal plate malformations. Am J Pathol 2000;156:1599-1612.

4. LeSage $G$, Alvaro D, Benedetti $A$, et al. Cholinergic system modulates growth, apoptosis, and secretion of cholangiocytes from bile ductligated rats. Gastroenterology 1999;117:191-199.

5. Marzioni $\mathrm{M}$, Glaser $\mathrm{S}$, Francis $\mathrm{H}$, et al. Autocrine/paracrine regulation of the growth of the biliary tree by the neuroendocrine hormone serotonin. Gastroenterology 2005;128:121-137.

6. Fava G, Marucci L, Glaser S, et al. Gamma-Aminobutyric acid inhibits cholangiocarcinoma growth by cyclic AMP-dependent regulation of the protein kinase $A /$ extracellular signal-regulated kinase $1 / 2$ pathway. Cancer Res 2005;65:11437-11446.

7. Glaser S, Alvaro D, Francis $H$, et al. Adrenergic receptor agonists prevent bile duct injury induced by adrenergic denervation by increased cAMP levels and activation of Akt. Am J Physiol Gastrointest Liver Physiol 2006;290:G813-G826.

8. Roskams T, van den Oord JJ, De Vos R, et al. Neuroendocrine features of reactive bile ductules in cholestatic liver disease. Am J Pathol 1990;137:1019-1025.

9. Uyama N, Geerts A, Reynaert H. Neural connections between the hypothalamus and the liver. Anat Rec A Discov Mol Cell Evol Biol 2004;280:808-820.
10. Holzer P. Efferent-like roles of afferent neurons in the gut: blood flow regulation and tissue protection. Auton Neurosci 2006; 125:70-75.

11. Goehler LE, Sternini C. Calcitonin gene-related peptide innervation of the rat hepatobiliary system. Peptides 1996;17:209-217.

12. Tiegs G, Bang R, Neuhuber WL. Requirement of peptidergic sensory innervation for disease activity in murine models of immune hepatitis and protection by beta-adrenergic stimulation. J Neuroimmunol 1999;96:131-143.

13. Rosenfeld MG, Mermod JJ, Amara SG, et al. Production of a novel neuropeptide encoded by the calcitonin gene via tissue-specific RNA processing. Nature 1983;304:129-135.

14. Poyner DR. Calcitonin gene-related peptide: multiple actions, multiple receptors. Pharmacol Ther 1992;56:23-51.

15. Amara SG, Arriza JL, Leff SE, et al. Expression in brain of a messenger RNA encoding a novel neuropeptide homologous to calcitonin generelated peptide. Science 1985;229:1094-1097.

16. Beglinger $\mathrm{C}$, Born $\mathrm{W}$, Hildebrand $\mathrm{P}$, et al. Calcitonin gene-related peptides I and II and calcitonin: distinct effects on gastric acid secretion in humans. Gastroenterology 1988;95:958-965.

17. Chang CP, Pearse II RV, O'Connell S, et al. Identification of a seven transmembrane helix receptor for corticotropin-releasing factor and sauvagine in mammalian brain. Neuron 1993;11:1187-1195.

18. McLatchie LM, Fraser NJ, Main MJ, et al. RAMPs regulate the transport and ligand specificity of the calcitonin-receptor-like receptor. Nature 1998;393:333-339.

19. Hay DL, Poyner DR, Sexton PM. GPCR modulation by RAMPs. Pharmacol Ther 2006;109:173-197.

20. Evans BN, Rosenblatt MI, Mnayer LO, et al. CGRP-RCP, a novel protein required for signal transduction at calcitonin gene-related peptide and adrenomedullin receptors. J Biol Chem 2000;275:31438-31443.

21. Prado MA, Evans-Bain B, Oliver KR, et al. The role of the CGRP-receptor component protein (RCP) in adrenomedullin receptor signal transduction. Peptides 2001;22:1773-1781.

22. Conner AC, Simms J, Howitt SG, et al. The second intracellular loop of the CGRP-receptor provides molecular determinants for signal transduction and cell-surface expression. J Biol Chem 2005;281: 1644-1651.

23. Anderson LE, Seybold VS. Calcitonin gene-related peptide regulates gene transcription in primary afferent neurons. J Neurochem 2004;91:1417-1429.

24. Francis $\mathrm{H}$, Glaser $\mathrm{S}$, Ueno $\mathrm{Y}$, et al. cAMP stimulates the secretory and proliferative capacity of the rat intrahepatic biliary epithelium through changes in the PKA/Src/MEK/ERK1/2 pathway. J Hepatol 2004;41: 528-537.

25. Zhang L, Hoff AO, Wimalawansa SJ, et al. Arthritic calcitonin/alpha calcitonin gene-related peptide knockout mice have reduced nociceptive hypersensitivity. Pain 2001;89:265-273.

26. Yin $\mathrm{H}$, Chao L, Chao J. Adrenomedullin protects against myocardial apoptosis after ischemia/reperfusion through activation of Akt-GSK signaling. Hypertension 2004;43:109-116.

27. Miyoshi H, Rust C, Roberts PJ, et al. Hepatocyte apoptosis after bile duct ligation in the mouse involves Fas. Gastroenterology 1999;117:669-677.

28. Ishii M, Vroman B, LaRusso NF. Isolation and morphological characterization of bile duct epithelial cells from normal rat liver. Gastroenterology 1989;97:1236-1247.

29. LeSage G, Glaser $S$, Marucci L, et al. Acute carbon tetrachloride feeding induces damage of large but not small cholangiocytes from BDL rat liver. Am J Physiol Gastrointest Liver Physiol 1999;276:G1289-G1301.

30. LeSage G, Alvaro D, Glaser S, et al. Alpha-1 adrenergic receptor agonists modulate ductal secretion of $\mathrm{BDL}$ rats via $\mathrm{Ca}^{(2+)}$ - and PKCdependent stimulation of CAMP. Hepatology 2004;40:1116-1127.

31. Gaudio E, Barbaro B, Alvaro D, et al. Vascular endothelial growth factor stimulates rat cholangiocyte proliferation via an autocrine mechanism. Gastroenterology 2006;130:1270-1282.

32. Vroman B, LaRusso NF. Development and characterization of polarized primary cultures of rat intrahepatic bile duct epithelial cells. Lab Invest 1996;74:303-313.

33. Roh J, Chang CL, Bhalla A, et al. Intermedin is a calcitonin/calcitonin gene-related peptide family peptide acting through the calcitonin receptor-like receptor/receptor activity-modifying protein receptor complexes. J Biol Chem 2004;279:7264-7274. 
34. Wang X, Fiscus RR, Tang Z, et al. CGRP in the serum of endotoxintreated rats suppresses lymphoproliferation. Brain Behav Immun 1994;8:282-292.

35. Hsu JH, Yeh JL, Dai ZK, et al. Increased circulating calcitonin generelated peptide in congestive heart failure caused by congenital heart disease. Int Heart J 2005;46:867-875.

36. Kato A, Gores GJ, LaRusso NF. Secretin stimulates exocytosis in isolated bile duct epithelial cells by a cyclic AMP-mediated mechanism. J Biol Chem 1992;267:15523-15529.

37. Glaser S, Alvaro D, Roskams T, et al. Dopaminergic inhibition of secretin-stimulated choleresis by increased PKC-gamma expression and decrease of PKA activity. Am J Physiol Gastrointest Liver Physiol 2003;284:G683-G694.

38. Collado B, Sanchez MG, Diaz-Laviada I, et al. Vasoactive intestinal peptide (VIP) induces c-fos expression in LNCaP prostate cancer cells through a mechanism that involves $\mathrm{Ca}^{2+}$ signaling. Implications in angiogenesis and neuroendocrine differentiation. Biochim Biophys Acta 2005;1744:224-233.

39. Mano $\mathrm{Y}$, Ishii M, Kisara N, et al. Duct formation by immortalized mouse cholangiocytes: an in vitro model for cholangiopathies. Lab Invest 1998;78:1467-1468.

40. Demorrow S, Glaser S, Francis $\mathrm{H}$, et al. Opposing actions of endocannabinoids on cholangiocarcinoma growth: recruitment of fas and fas ligand to lipid rafts. J Biol Chem 2007;282: 13098-13113.

41. Gigliozzi A, Alpini G, Baroni GS, et al. Nerve growth factor modulates the proliferative capacity of the intrahepatic biliary epithelium in experimental cholestasis. Gastroenterology 2004;127:1198-1209.

42. Wang $\mathrm{H}$, Vohra BP, Zhang $\mathrm{Y}$, et al. Transcriptional profiling after bile duct ligation identifies PAI-1 as a contributor to cholestatic injury in mice. Hepatology 2005;42:1099-1108.

43. Bendtsen F, Schifter S, Henriksen JH. Increased circulating calcitonin gene-related peptide (CGRP) in cirrhosis. J Hepatol 1991;12:118-123.
44. Henriksen $\mathrm{JH}$, Moller S, Schifter S, et al. High arterial compliance in cirrhosis is related to low adrenaline and elevated circulating calcitonin gene related peptide but not to activated vasoconstrictor systems. Gut 2001;49:112-118.

45. Lee FY, Lin HC, Tsai YT, et al. Plasma substance P levels in patients with liver cirrhosis: relationship to systemic and portal hemodynamics. Am J Gastroenterol 1997;92:2080-2084.

46. Tahan V, Avsar E, Karaca C, et al. Adrenomedullin in cirrhotic and noncirrhotic portal hypertension. World J Gastroenterol 2003;9:2325-2327.

47. Henriksen JH, Moller S, Schifter S, et al. Increased arterial compliance in decompensated cirrhosis. J Hepatol 1999;31:712-718.

48. Akiyoshi H, Gonda T, Terada T. A comparative histochemical and immunohistochemical study of aminergic, cholinergic and peptidergic innervation in rat, hamster, guinea pig, dog and human livers. Liver 1998;18:352-359.

49. Alpini G, Lenzi R, Zhai WR, et al. Bile secretory function of intrahepatic biliary epithelium in the rat. Am J Physiol Gastrointest Liver Physiol 1989;257:G124-G133.

50. Gaudio E, Barbaro B, Alvaro D, et al. Administration of r-VEGF-A prevents hepatic artery ligation-induced bile duct damage in bile duct ligated rats. Am J Physiol Gastrointest Liver Physiol 2006;291: G307-G317.

51. Glaser S, Alvaro D, Ueno Y, et al. Gastrin reverses established cholangiocyte proliferation and enhanced secretin-stimulated ductal secretion of $\mathrm{BDL}$ rats by activation of apoptosis through increased expression of $\mathrm{Ca}^{2+}$-dependent PKC isoforms. Liver Int 2003;23:78-88.

52. Glaser S, Katki K, DeMorrow S, et al. Substance P stimulates biliary growth during cholestasis induced by extrahepatic bile duct obstruction (BDL) via activation of ERK1/2/p38/CREB signaling mechanisms. Hepatology 2006;44:602A.

53. Mulderry PK, Ghatei MA, Spokes RA, et al. Differential expression of alpha-CGRP and beta-CGRP by primary sensory neurons and enteric autonomic neurons of the rat. Neuroscience 1988;25:195-205. 